\title{
Orofacial Praxis Abilities in Children with Speech Disorders
}

\author{
Ana Paula Coitino Bertagnolli ${ }^{1}$ Marileda Barichello Gubiani ${ }^{1}$ Marizete Ceron ${ }^{1}$ Márcia Keske-Soares ${ }^{1}$ \\ ${ }^{1}$ Department of Speech Therapy, Universidade Federal de Santa Maria, \\ Santa Maria, Rio Grande do Sul, Brazil \\ Int Arch Otorhinolaryngol 2015;19:286-292. \\ Address for correspondence Marileda Barichello Gubiani, MSc, \\ Departamento de Fonoaudiologia, Universidade Federal de Santa \\ Maria, Avenida Roraima 1000, Santa Maria, RS 97105900, Brazil \\ (e-mail: mari_gubiani@yahoo.com.br; mari_gubiani@hotmail.com).
}

\begin{abstract}
Introduction Phonological development occurs in a gradual manner until the age of 7 years. The phonological system is constructed in a similar way for all children, despite presenting some variations in terms of age, paths taken, or repair strategies used. Objective To compare the orofacial praxis abilities of children with typical phonological development (DFT), children with phonetic-phonological impairment (DFoFe), and children with phonological impairment (DF), using two tests to assess the orofacial praxis abilities.

Methods The sample consisted of 82 subjects between 4 and 8 years of age who attended public schools (from preschool to the second year of secondary school) in the city of Santa Maria, Brazil. Of these, 29 were diagnosed with DFT, 29 with DF, and 24 with DFoFe; much of this sample was male. Two tests of praxis abilities and assessment of the stomatognathic system were administered. Statistical analysis was performed using the

\section{Keywords}

- speech

- child

- articulation disorder

- stomatognathic system

- speech disorders chi-square test, with a significance level of $5 \%$.

Results Generally children with DFoFe underperformed in tests of praxis when compared with subjects with DF and DFT.

Conclusion The results showed that children with DFoFe have more difficulty in orofacial praxis abilities than subjects in the other groups studied. This result could be expected, because subjects with DFoFe show changes in both phonetic and phonological levels of speech.
\end{abstract}

\section{Introduction}

Children are exposed to their mother tongue from the time they are born through external stimuli, such as the parents' conversations and songs they hear, among others. By hearing the language, children construct their phonological system, in which some rules and patterns must be followed so to reach the typical pattern of language acquisition. ${ }^{1}$

The phonological system is constructed in a similar way for all children, despite presenting some variations in terms of age, paths taken, or repair strategies used. During this devel-

received

July 11, 2014

accepted

March 25, 2015

published online

June 3, 2015 opment, each child improves the articulatory movements so that around 6 years of age, speech is intelligible to people living outside his or her home environment. ${ }^{2}$

The phonological development occurs in a gradual manner until the age of 7 . In the first year of a child's life, the phonological system is prelinguistic and is characterized by vocalization sounds present or not in the adult target language. ${ }^{3}$ The phonetic acquisition also happens gradually and quickly, completing at around 5 or 6 years old, at which time the child reaches maturity and has full articulation of the phonetic inventory. ${ }^{4}$
Copyright $\odot 2015$ by Thieme Publicações License terms Ltda, Rio de Janeiro, Brazil 
During the development of speech, the child may have some impairments from the typical acquisition, such as phonological impairment (DF), which is defined as a difficulty speaking and is characterized by inappropriate use of sounds, which may involve errors in production, perception, or organization of these sounds. ${ }^{5}$ Although the cause of DF is the subject of many studies, it is not yet fully defined. ${ }^{6}$

Phonetic impairment (DFe) is characterized by a motor and sensory incompetency for the production of speech sounds or by a disorder in the anatomical mechanism of speech production. ${ }^{3} \mathrm{DFe}$ is related to a difficulty in functionality and directly linked to the motor aspect of the execution of the speech sounds. ${ }^{7}$

In some children, these two changes can be combined, resulting in phonetic-phonological impairment (DFoFe), in which both aspects (motor and organizational) are changed.

For proper speech production, it is necessary for the vocal tract to present a minimal development of its structure and its motor abilities. Thus, a prior coordination of the phonological articulatory organs is crucial, so that there is a precise articulatory control by means of the movement of the orofacial structures in implementing the stomatognathic functions. ${ }^{8,9}$

Early in development, motor control of speech is not fully established. The movements of the lips, tongue, and jaw are altered, enabling the child to achieve higher levels of precision and articulatory coordination. When this refinement does not occur, the output of speech becomes compromised. $^{10}$

Orofacial praxis is defined as an ability to perform skilled movements of speech and of the muscles of the phonological articulatory organs after verbal command or demonstration. ${ }^{11}$ The acquisition of the praxis occurs progressively along with the development of speech and is considered a functional learning and a result of interaction with actual speech production. ${ }^{7}$ The development of these motor abilities starts around 2 years of age, and by 12 years, children should present a complete development of these skills and should already be able to perform fine, efficient, and coordinated movements. $^{12}$

A study performed in children with typical phonological development (DFT) and with DF assessed the praxis skills by means of two tests of praxis ${ }^{13}$ : the Orofacial Praxis Test ${ }^{12}$ and Protocol of assessment of the Articulatory and Bucco-facial Praxis. ${ }^{14}$ The results showed that with increasing age there was an improvement in the performance of tasks of praxis. Still, when the praxis tasks were performed after imitation, the results were better than after verbal request. ${ }^{13}$ The author observed that children with DF have more changes of orofacial, speech, and buccofacial praxis compared with children with DFT. ${ }^{13}$

Another study also observed that children with DF have more difficulty in moving the articulators during tests of praxis when compared with children without phonological deficit. ${ }^{15}$ Another study observed that the inclusion of the work with orofacial praxis abilities (activities drawn from tests of praxis in question) favors the improvement in changes in the speech of children with DF, suggesting that the levels may be related. ${ }^{9}$
Although this is a topic of great relevance for speech therapy clinical practice, there is a great lack of studies involving the speech-language pathology (DF, DFE, and DFoFe) associated with motor skills of speech sounds, among them, the orofacial praxis abilities. It is clear that there are not many studies in this area and that a lack of protocols and standardized scales exists in Brazil to assess orofacial praxis abilities, which necessitate further studies with these protocols and even creating others.

Thus, the aim of this study is to compare the orofacial praxis abilities in children with DFT, children with DF, and children with DFoFe. This comparison was performed by administering two tests of orofacial praxis abilities. These have not yet been validated for the Brazilian population; however, they are most often used in research in Brazil.

\section{Methods}

This research is part of a project duly registered and approved by the Research Ethics Committee of an Institution of Higher Education, on number 0093.0.243.000-9. All caretakers signed the informed consent form, as did those responsible for the participating schools.

The sample consisted of 82 subjects of municipal public schools, 18 girls and 66 boys with ages ranging from 4 to 8 years. The subjects attended grades from preschool to the second year of the elementary schools on the outskirts of the city of Santa Maria, Brazil. The participants were divided into three different groups: DFT consisting of 29 children; DF, with 29; and DFoFe, with 24.

For diagnosis, children were administered the Phonological Assessment of the Child ${ }^{16}$ and the articulatory exam, an assessment developed in an Institution of Higher Education, which includes all the phonemes of the Portuguese language in all positions. This test assesses the repetition, as well as stimulability to a particular sound. Subjects with DFT showed no change in speech, both in the phonetic as well as the phonological levels. Children of the DF group showed alterations only in the phonological level, and finally, DFoFe subjects had changes in both phonetic and phonological levels.

The criteria for inclusion of subjects in the study were:

- permission of parents or guardians by signing the consent form and the verbal agreement of the child to participate in the research

- hearing screening with no special peculiarities

- absence in the history of neurologic problems and psychological and/or cognitive changes (children underwent a detailed and complete anamnesis, and when any data were suggestive of alteration, the child was excluded from the sample)

- understanding spoken language appropriate to the age group, which was observed by means of an informal conversation in which there was consistency and organization of the child to tell a story and whether the vocabulary used was appropriate for age and education of the child 
- adequate expressive language ability (except for phonological changes in the DF group and phonetic-phonological for the DFoFe group)

- no changes in the phonological development or articulatory production of speech sounds introduced in the DFT group

Children were excluded if they had a history of neurologic, psychological, and/or emotional changes, as well as agitated behavior and/or difficulty concentrating, evidenced during speech screening; previous history of hearing complaints and/or hearing screening suggestive of alteration; alterations evident in aspects of language other than the phonological; or previous speech therapy. The linguistic aspects were assessed in an informal conversation, in which the consistency and organization of the child to tell a story were assessed as well as whether the vocabulary used was appropriate for age and education of the child.

The following procedures were performed to collect data: speech anamnesis with parents/guardians; speech screening; hearing screening with Interacoustics AD-229 portable audiometer (Interacoustics, Assens, Denmark) in the frequencies of 500, 1,000, 2,000, and 4,000 Hz. Children with consistent responses in the frequencies tested at the level of $20 \mathrm{~dB}$ passed to the next step, and those with suspected hearing loss were referred for ear, nose, and throat examination and audiology; implementation of Phonological Assessment of Child $^{16}$; assessment of the stomatognathic system; and two orofacial praxis ability tests: the Orofacial Praxis Test ${ }^{12}$ and Protocol of assessment of the Articulatory and Bucco-facial Praxis. $^{14}$

The Orofacial Praxis Test is independent from the language for its application and was standardized with Italian children aged 4 to 8 years. ${ }^{12}$ The test assesses difficulties in performing movements and movement sequences using the orofacial muscles and makes the distinction between the type of gesture and type of verbal command. The test consists of 36 tasks, divided into 12 voiced and orofacial praxis and 6 motion sequences and parallel movements. The other instrument used for the assessment of the praxis was the Protocol of assessment of the Articulatory and Bucco-facial Praxis. ${ }^{14}$ This test aims to assess articulatory gestures, consisting of 24 buccofacial movements divided into six movements of lips, six of tongue, six of the face, and six articulatory movements.

The applications of both orofacial praxis testing and assessment of the stomatognathic system were conducted in an assessment session and lasted about an hour. The implementation sites were provided by the schools and were either a classroom or the library. The space provided by the school was quiet, and each child was assessed individually by the examiner to avoid embarrassment for the child.

The results were analyzed by comparing the praxis abilities of children with DFT, children with DFoFe, and children with DF from the two tests applied.

Statistical analysis was performed using descriptive statistics, using the frequency and percentages. The objective was to compare the groups regarding the variable "praxis," using the chi-square test and, when statistical significance was found, using the adjusted residues analysis. The level of significance considered was of $5 \%$ $(p<0.05)$.

\section{Results}

- Tables 1, 2, 3 and $\mathbf{4}$ present only the statistically significant results obtained. The first analyses refer to orofacial praxis and the voiced praxis of the Orofacial Praxis Test for the DFoFe, DF, and DFT groups. ${ }^{12}$ Significant results were not found for orofacial praxis in items "Cow noise," "Sheep sound," "Coughing," "Tongue clicking," "Buzz zzz," "Whistling," "Throwing a kiss." Also, the groups satisfactorily performed the movements of the variables "Showing the tongue" and "Smiling," and the variables "Blowing," "Filling the cheeks," "Biting the tongue," "Breathing through the nose," "Raising an eyebrow," and "Blinking" did not show significant results.

Using adjusted residues analysis, all the voiced praxis variables were associated with the group with DF, showing that these subjects have the ability to perform these praxes (-Table 1). Also, associations were observed among the nonperformance of the motion "To say 'ah' with the mouth open" and "To blow a raspberry" for the DTF group and the performance of the motion "To blow a raspberry" for the DFoFe group.

- Table 2 presents the motions sequences and the parallel motions of the Orofacial Praxis Test of the DFoFe, DF, and DFT groups, and all the subjects satisfactorily performed the sequence "Opening and closing the mouth" and the parallel movements. ${ }^{12}$ The results showed no statistically significant difference for the sequence of movements in the variables "Sticking the tongue and closing the mouth" and "Filling the cheeks and releasing by the nose" and for the parallel movements "Closing the eyes and opening the mouth" and "Biting the tongue and closing the mouth, saying 'ah."'

Thus, significant results were found for the sequences of movements "Showing the teeth, opening the mouth and closing the eyes," "Blowing, biting the lower lip and filling the cheeks," and "Sticking the tongue, touching the cheek with the tooth and throwing a kiss." There were significant results in the parallel movements of variables "Closing the teeth and raising the eyebrow," "Opening the mouth, protruding the tongue and saying 'ah,"' and "Closing the eyes, closing the mouth and breathing by the nose."

The Adjusted Residues Analysis results show that there was an association for the performance of the movement in the DF group in the variable "Opening the mouth, protruding the tongue and saying 'ah," and in the DFT group for the variable "Closing the eyes, closing the mouth and breathing by the nose" ( - Table 2 ). Also, there was an association with the nonperformance of the movement in the DFoFe group in the variables "Closing the teeth and raising the eyebrow," "Opening the mouth, protruding the tongue and saying 'ah,"” "Closing the eyes, closing the mouth and breathing by the nose." This shows that the children of the DFoFe group showed more difficulties in performing the praxis abilities. 
Table 1 Voiced praxis and orofacial praxis in the Orofacial Praxis Test ${ }^{11}$ in DFoFe, DF, and DFT groups

\begin{tabular}{|c|c|c|c|c|}
\hline \multirow[t]{2}{*}{ Voiced praxis and orofacial praxis } & \multicolumn{3}{|l|}{ Groups } & \multirow[t]{2}{*}{$p$ Value $^{a}$} \\
\hline & DFoFe, $n(\%)$ & $\mathrm{DF}, \boldsymbol{n}(\%)$ & DFT, $n(\%)$ & \\
\hline \multicolumn{5}{|l|}{ To say "ah" with open mouth } \\
\hline Yes & $20(29.0)$ & $28(40.6)$ & $21(30.4)$ & \multirow[t]{2}{*}{0.042} \\
\hline No & $4(30.8)$ & $1(7.7)$ & $8(61.5)$ & \\
\hline \multicolumn{5}{|l|}{ To clear the throat } \\
\hline Yes & $8(34.8)$ & $14(60.9)$ & $1(4.3)$ & \multirow[t]{2}{*}{0.001} \\
\hline No & $16(27.1)$ & $15(25.4)$ & $28(47.5)$ & \\
\hline \multicolumn{5}{|l|}{ To blow a raspberry } \\
\hline Yes & $22(36.1)$ & $27(44.3)$ & $12(19.7)$ & \multirow[t]{2}{*}{$<0.0001$} \\
\hline No & $2(9.5)$ & $2(9.5)$ & $17(81.0)$ & \\
\hline \multicolumn{5}{|l|}{ To ask for silence } \\
\hline Yes & $17(27.9)$ & $26(42.6)$ & $18(29.5)$ & \multirow[t]{2}{*}{0.049} \\
\hline No & $7(33.3)$ & $3(14.3)$ & $11(52.4)$ & \\
\hline \multicolumn{5}{|l|}{ To grit the teeth } \\
\hline Yes & $6(16.2)$ & $19(51.4)$ & $12(32.4)$ & \multirow[t]{2}{*}{0.011} \\
\hline No & $18(40)$ & $10(22.2)$ & $17(37.8)$ & \\
\hline \multicolumn{5}{|l|}{ To bite the lower lip } \\
\hline Yes & 10(18.9) & $24(45.3)$ & $19(35.8)$ & \multirow[t]{2}{*}{0.008} \\
\hline No & $14(48.3)$ & $5(17.2)$ & $10(34.5)$ & \\
\hline \multicolumn{5}{|l|}{ To touch the cheek with the tongue } \\
\hline Yes & $11(19)$ & $24(41.4)$ & $23(39.7)$ & 0.006 \\
\hline No & $13(54.2)$ & $5(20.8)$ & $6(25.0)$ & \\
\hline \multicolumn{5}{|l|}{ To yawn } \\
\hline Yes & $7(16.3)$ & $22(51.2)$ & $14(32.6)$ & \multirow[t]{2}{*}{0.003} \\
\hline No & $17(43.6)$ & 7 (17.9) & $15(38.5)$ & \\
\hline
\end{tabular}

Abbreviations: DFoFe, phonetic-phonological impairment; DF, phonological impairment; DFT, typical phonological development.

${ }^{a}$ Chi-square, with adjusted residues analysis.

The following analyses refer to the test of articulatory and buccofacial praxis. ${ }^{13}$ Statistically significant results were not noted in the articulation of $/ \mathrm{p} /, / \mathrm{t} /, / \mathrm{k} /, / \mathrm{f} /, / \mathrm{l} /$ for none of the DFoFe, DF, and DFT groups ( - Table 2). There was a significant result only for the variable "Pataka articulation."

Results in - Table 3 show that there is an association to carrying out the movement in the DFT group and for the nonperformance of the movement in the DT group. Therefore, to perform this sequence of sounds, greater phonological organization is required, which may be compromised in cases of DF.

- Table 4 shows the movement of the lips, tongue, and face in DFoFe, DF, and DFT groups. Statistically significant results were not found in lip movement for the variables "Throwing a kiss," "Blowing," "Showing the teeth," "Biting the lower lip" and "Biting upper lip"; therefore, they are not shown in the table. Only the variable "Move lips forward and backward" will be presented, which showed significant results.

There was no significant association in movements of the tongue for the variables "Protrude the tongue without the support from the lips," "Keeping the tongue for 4 seconds without the support of the teeth," and "Touching the 4 corners of the mouth"; therefore, they will not be presented in the table. Significant results occurred only for the variables "Lowering the tongue toward the chin" and "Licking the lips."

Here were no significant results in face movements for the variables "Frowning," "Blink alternately," "Mimic of crying," "Fill cheeks with air," "Push air in the cheeks from one side to the other." There was a significant result only for the variable "Sucking in the cheeks" (-Table 4).

The results ( - Table 4 ) have evidenced the association from the adjusted residues analysis of the variable "Move lips forward and backward" to perform the motion in the DFoFe group and for the nonperformance of the motion in the DFT group.

Also, an association for the nonperformance of the motion for the DFT group is noted, and in the "Licking the lips" variable, there was an association for the performance of the motion in the DFoFe group and for the nonperformance of the motion in the DFT group. Also noted 
Table 2 Parallel movements and sequence of movements of the test the Orofacial Praxis Test ${ }^{11}$ in DFoFe, DF, and DFT groups

\begin{tabular}{|c|c|c|c|c|}
\hline \multirow[t]{2}{*}{ Praxis abilities } & \multicolumn{3}{|l|}{ Groups } & \multirow[t]{2}{*}{ p Value $^{\text {a }}$} \\
\hline & DFoFe, $n(\%)$ & $\mathrm{DF}, \boldsymbol{n}(\%)$ & DFT, $n(\%)$ & \\
\hline \multicolumn{5}{|c|}{ Showing teeth, opening mouth and closing eyes } \\
\hline Yes & $9(17.3)$ & $22(42.3)$ & $21(40.4)$ & \multirow[t]{2}{*}{0.007} \\
\hline No & $15(50.0)$ & $7(23.3)$ & $8(26.7)$ & \\
\hline \multicolumn{5}{|c|}{ Blowing, biting lower lip and filling cheeks with air } \\
\hline Yes & $10(18.2)$ & $20(36.4)$ & $25(45.5)$ & \multirow[t]{2}{*}{0.003} \\
\hline No & $14(51.9)$ & $9(33.3)$ & $4(14.8)$ & \\
\hline \multicolumn{5}{|c|}{ Showing tongue, touching cheek with the tooth and throwing a kiss } \\
\hline Yes & 6 (13.6) & 16 (36.4) & $22(50.0)$ & \multirow[t]{2}{*}{0.001} \\
\hline No & $18(47.4)$ & $13(34.2)$ & $7(18.4)$ & \\
\hline \multicolumn{5}{|c|}{ Closing eyebrows and raising an eyebrow } \\
\hline Yes & $8(17.8)$ & $22(48.9)$ & $15(33.3)$ & \multirow[t]{2}{*}{0.008} \\
\hline No & $16(43.2)$ & $7(18.9)$ & $14(37.8)$ & \\
\hline \multicolumn{5}{|c|}{ Opening mouth, protruding tongue and saying "ah" } \\
\hline Yes & $9(17.0)$ & $23(43.4)$ & $21(39.6)$ & \multirow[t]{2}{*}{0.004} \\
\hline No & $15(51.7)$ & $6(20.7)$ & $8(27.6)$ & \\
\hline \multicolumn{5}{|c|}{ Closing eyes, closing mouth and breathing through the nose } \\
\hline Yes & $12(20.0)$ & $21(35.0)$ & $27(45.0)$ & \multirow[t]{2}{*}{0.002} \\
\hline No & $12(54,5)$ & $8(36,4)$ & $2(9,1)$ & \\
\hline
\end{tabular}

Abbreviations: DFoFe, phonetic-phonological impairment; DF, phonological impairment; DFT, typical phonological development. ${ }^{\mathrm{a} C h i-s q u a r e .}$

is an association for the performance of the motion in the "Sucking in the cheeks" variable for the DFoFe group. This praxis was performed satisfactorily by $39.2 \%$ of these subjects.

\section{Discussion}

The results showed that subjects in the DFoFe group underperformed in two tests of applied praxis, followed by subjects with DF and, finally, children with DFT, who performed better. This was observed probably because the DFoFe group has larger commitments that go beyond the organization of phonemes and include the motor realization of these.

Studies have mentioned that subjects with speech disorder (DF) showed poorer performance on tests of orofacial praxis abilities compared with children with typical phonological acquisition. ${ }^{13,15}$ These findings are similar to the findings in this study that compared different groups of children with speech change and DFT.

Difficulty in performing some orofacial praxis abilities was found to occur along with DF and/or DFoFe, which is consistent with the literature., ${ }^{9,15}$

Motor problems are a common comorbidity in children with speech disorders, suggesting an abnormality between planning and processing of motor movements that affect both speech and fine motor performance. ${ }^{17}$ Thus, the speech impairment is not an isolated event, but occurs with other phenomena, and the motor deficit may be one of them. ${ }^{17}$

A relationship exists between the maturation of the speech motor processing and the phonological development.

Table 3 Articulation point, task of the assessment test of the articulatory and buccofacial praxis ${ }^{13}$, in groups DFoFe, DF and DFT

\begin{tabular}{|l|l|l|l|l|}
\hline \multirow{2}{*}{ Articulation point } & \multicolumn{2}{|l|}{ Groups } & \multirow{2}{*}{$\boldsymbol{p}$ Value $^{\mathbf{a}}$} \\
\cline { 2 - 4 } & DFoFe, $\boldsymbol{n}(\%)$ & DF, $\boldsymbol{n}(\%)$ & DFT, $\boldsymbol{n}(\%)$ & \\
\hline Pataka articulation & & & & \\
\hline Yes & $17(27.9)$ & $16(26.3)$ & $28(45.9)$ & 0.001 \\
\hline No & $7(33.3)$ & $13(61.9)$ & $1(4.8)$ & \\
\hline
\end{tabular}

Abbreviations: DFoFe. phonetic-phonological impairment; DF. phonological impairment; DFT, typical phonological development.

Statistical test: Chi-square. 
Table 4 Movement of lips, tongue, and face in the articulatory and buccofacial praxis assessment test ${ }^{13}$ in groups DFoFe, DF, and DFT

\begin{tabular}{|c|c|c|c|c|}
\hline \multirow[b]{2}{*}{ Movement } & \multicolumn{3}{|l|}{ Groups } & \multirow[b]{2}{*}{ p Value ${ }^{a}$} \\
\hline & DFoFe, $n(\%)$ & DF, $n(\%)$ & DFT, $n(\%)$ & \\
\hline \multicolumn{5}{|c|}{ Movement of lips } \\
\hline \multicolumn{5}{|c|}{ To move lips forward and backward } \\
\hline Yes & $24(33)$ & $28(38.9)$ & $20(27.8)$ & \multirow[t]{2}{*}{0.001} \\
\hline No & $0(0.0)$ & $1(10.0)$ & $9(90.0)$ & \\
\hline \multicolumn{5}{|c|}{ Movement of tongue } \\
\hline \multicolumn{5}{|c|}{ Lowering the tongue toward the chin } \\
\hline Yes & $23(31.1)$ & $28(37.8)$ & $23(31.1)$ & \multirow[t]{2}{*}{0.047} \\
\hline No & $1(12.5)$ & $1(12.5)$ & $6(75.0)$ & \\
\hline \multicolumn{5}{|c|}{ Licking lips } \\
\hline Yes & $24(32.9)$ & $27(37.0)$ & $22(30.1)$ & \multirow[t]{2}{*}{0.014} \\
\hline No & $0(0.0)$ & $2(22.2)$ & $7(77.8)$ & \\
\hline \multicolumn{5}{|c|}{ Movements of the face } \\
\hline \multicolumn{5}{|c|}{ Sucking in the cheeks } \\
\hline Yes & $20(39.2)$ & $15(29.4)$ & $16(31.4)$ & \multirow[t]{2}{*}{0.038} \\
\hline No & $4(12.9)$ & $14(45.2)$ & $13(41.9)$ & \\
\hline
\end{tabular}

Abbreviations: DFoFe, phonetic-phonological impairment; DFo, phonological impairment; DFT, typical phonological development. ${ }^{\mathrm{a} C h i-s q u a r e .}$

Children with DF had more immature speech motor processing than children with typical phonological development. ${ }^{15}$ Therefore, children with impairments in speech and language may show speech motor control deficit. ${ }^{9,15,18}$ The fact was observed mainly in the group with DFoFe, in which a worse performance was obtained in both tests of praxis, as these subjects had changes in both phonetic and phonological levels.

A study showed that subjects with articulatory changes underperformed compared with a control group (children with no articulatory changes) for all the tasks in the Protocol of assessment of the Articulatory and Bucco-facial Praxis test. ${ }^{14,19}$ In this study, subjects with abnormal articulation of phonemes (DFoFe group) showed further structural change (the vast majority had anterior open bite) in addition to changes in the phonological level. Information contributes to the group with articulatory change presenting lower performance on tests of praxis abilities.

The research mentions that a correlation between the tone and nonverbal praxis of language is possible, suggesting that the muscle condition can interfere with the performance of the sequence of movements, which may influence the accuracy in the articulation of speech sounds. ${ }^{20}$ In this study, there are children with DFT who had difficulty in performing the praxis assessed (-Tables 1, 2, 3 and 4); however, the majority of these groups show no changes.

One of the deficits found in children with speech impairments may be neuromuscular. ${ }^{21}$ The distribution of the muscle spindle in the articulators, such as the masseter, temporal, among others, are of great importance for the performance of speech, emphasizing that the oral musculature is relevant to the articulation of speech sounds. ${ }^{21}$ Thus, the structures involved in phonation show changes of muscle tension and praxis and may interfere in the production of speech sounds. ${ }^{12}$

Oral motor learning can be impaired in many developmental disorders in which the speech is too. The oral musculature is relevant for the phonemes to be adequately articulated. ${ }^{19}$ Still, complex oral movements have a significant correlation with the language (i.e., children with good language abilities also have better oral motor abilities), which is in agreement with this study, as children with DFT showed the best results in the praxis abilities assessed.

In speech therapy clinical practice, when certain sounds are taught to children, some have difficulties in performing the phoneme, even if isolated. If the orofacial praxis abilities are assessed, it can be inferred that most of them have changed. When working with these abilities, along with the implementation of the sounds, there is the possibility not only to facilitate learning, as well as reducing the time of speech therapy, because the execution of phonemes is nothing more than a sequence of praxis abilities. This result was also mentioned in a study that tried to associate the therapy with an essentially phonological basis to the stimulation of the orofacial praxis abilities. ${ }^{9}$

\section{Conclusions}

This study, which aimed to verify the orofacial praxis abilities in subjects with DFT, DF and DFoFe, showed that children 
with DFoFe had greater difficulties in performing the praxis abilities required during the two tests applied. ${ }^{12,14}$

This study is significant in that it shows that other components may be altered in children with speech impairments, which should be focused on during the speech therapy. This further contributes to the effectiveness in the therapy of these disorders, as therapy may be planned to include all the child's difficulties.

Further studies on the topic are suggested, due to the extreme relevance for speech therapy clinical practice and the lack of studies in the area. In addition, new protocols should be created and/or existing protocols should be standardized and validated.

\section{References}

1 Lamprecht RR, org. Aquisição fonológica do português: perfil de desenvolvimento e subsídios para terapia. Porto Alegre, Brazil: Artmed; 2004

2 Wertzner HF, Galea DES, Almeida RC. Uso do processo fonológico de simplificação de velar em crianças de 2,1 a 3,0 anos de idade. J Bras Fonoaudiol 2001;2(8):233-288

3 Wertzner HF. Fonologia: Desenvolvimento e alterações. In: Fernandes FDM, Mendes BC, Navas ALPGP, eds. Tratado de fonoaudiologia. 2nd ed. São Paulo, Brazil: Rocca; 2010

4 American Speech-Language-Hearing Association. Incidence and prevalence of communication disorders and hearing loss in children. 2008. Available at: http://www.asha.org/public/hearing/ Prevalence-and-Incidence-of-Hearing-Loss-in-Children/

5 Keske-Soares M, Mota HB, Pagliarin KC, Ceron MI. Estudo sobre os ambientes favoráveis á produção da líquida não lateral /r/ no tratamento do desvio fonológico. Rev Soc Bras Fonoaudiol 2007; 12(1):48-54

6 Preston J, Edwards ML. Phonological awareness and types of sound errors in preschoolers with speech sound disorders. J Speech Lang Hear Res 2010;53(1):44-60

7 Santana AP, Machado MLACC, Rosa KB, Souza MF, Marques JM. O articulatório e o fonológico na clinica da linguagem: da teoria à pratica. Rev CEFAC 2010;12(2):193-201
8 Morales RC. Terapia da regulação orofacial. São Paulo, Brazil: Memnon; 1999

9 Gubiani MB, Keske-Soares M. Evolução fonológica de crianças com desvio fonológico submetidas a diferentes abordagens terapêuticas. Rev CEFAC 2014;16(2):663-671

10 Uchoa TN, Payao LMC. Apraxia da fala adquirida e desenvolvimental: semelhanças e diferenças. Rev Soc Bras Fonoaudiol 2008; 13(2):193-202

11 Kools JA, Tweedie D. Development of praxis in children. Percept Mot Skills 1975;40(1):11-19

12 Bearzotti F, Tavano A, Fabbro F. Development of orofacial praxis of children from 4 to 8 years of age. Percept Mot Skills 2007;104(3 Pt 2):1355-1366

13 Marini C. Habilidades práxicas orofaciais em crianças com desvio fonológico evolutivo e com desenvolvimento fonológico típico [dissertation]. Universidade Federal de Santa Maria; Santa Maria/RS 2010

14 Hage SRV. Dispraxia articulatória: correlações com o desenvolvimento da linguagem. In: Marchesan I, Zorzi J, eds. Anuário CEFAC de fonoaudiologia. Rio de Janeiro, Brazil: Revinter 1999-2000: $119-130$

15 Souza TNU, Avila CRB. Gravidade do transtorno fonológico, consciência fonológica e praxia articulatória em pré-escolares. Rev Soc Bras Fonoaudiol 2011;16(2):182-188

16 Yavas M, Hernandorena CLM, Lamprecht RR. Avaliação Fonológica da Criança. Porto Alegre, Brazil: Artmed; 1991

17 Müürsepp I, Ereline J, Gapeyeva H, Pääsuke M. Motor Performance in 5-year-old preschool children with developmental speech and language disorders. Tartu, Estônia: University of Tartu, Institute of exercise of biology and physiotherapy; 2009

18 Shriberg LD, Campbell TF, Karlsson HB, Brown RL, McSweeny JL, Nadler CJ. A diagnostic marker for childhood apraxia of speech: the lexical stress ratio. Clin Linguist Phon 2003;17(7):549-574

19 Campos DBP. Comparação das praxias buco-faciais, articulatórias e manuais entre crianças com alterações articulatórias e normais [monografia]. São Paulo, Brazil: Universidade Sagrado Coração; 2000

20 Farias SR, Ávila CRB, Vieira MM. Relação entre fala, tônus e praxia não verbal do sistema estomatognático em pré-escolares. PróFono Rev de Atual Cient 2006;18(3):267-276

21 Ruscello DM. Nonspeech oral motor treatment issues related to children with developmental speech sound disorders. Lang Speech Hear Serv Sch 2008;39(3):380-391 